\title{
Applying Quality Function Deployment in Food Safety Management
}

\author{
Tim Sweet \\ Revolve Business Consulting Ltd. \\ Calgary, Alberta, Canada \\ www.revolveconsulting.com \\ Jaydeep Balakrishnan \\ Haskayne School of Business \\ University of Calgary \\ Calgary, Alberta T2N 1N4, Canada \\ Ph: (403) 2207844 \\ Fax: (403) 2103327
}

Internet: Jaydeep.Balakrishnan@ @askayne.ucalgary.ca

\author{
Brad Robertson \\ CN Rail \\ Edmonton, Alberta, Canada \\ Jennifer MacFarlane \\ PennWest Energy Trust \\ Calgary, Alberta, Canada \\ Sarah Karim \\ CP Rail \\ Calgary, Alberta, Canada
}

Author for Correspondence: Jaydeep Balakrishnan 


\title{
Applying Quality Function Deployment in Food Safety Management
}

\author{
Category: Case studies
}

\section{Structured Abstract}

\section{Purpose of this paper}

This paper reports on a case study conducted to help plan a rollout process for Hazard Analysis and Critical Control Point (HACCP) type food safety policies at a frozen pie facility in Calgary, Alberta, Canada.

\section{Design/methodology/approach}

Existing company policies were prioritized using a Quality Function Deployment tool, which quantified the qualitative material in the original manual based on a number of developed criteria. Interrelations between the different required tasks were also quantified to facilitate effective implementation.

\section{Findings}

The use of Quality Function Deployment was shown to be useful in speeding up the implementation of food safety policies in the facility

\section{Practical implications (if applicable)}

Quality Function Deployment, originally from new product design, proved a useful one when applied to HACCP implementation.

\section{What is original/value of paper.}

This paper discusses the use of product development tools to facilitate the effective introduction of HACCP like procedures. Thus it will be of use to academics and practitioners interested in HACCP implementation.

Keywords: HACCP, food manufacturing and safety, quality function deployment, process improvement, case study 


\section{Applying Quality Function Deployment in Food Safety Management}

\section{Introduction}

This paper reports on a case study in which the authors helped develop a process to facilitate implementation of a food safety programme within a frozen pie facility located in Calgary, Alberta, Canada. The owner of the plant was anxious to establish and document the facility's health and safety standards within six to nine months in order to secure a major contract with a large Canadian grocery chain. Although this particular contract was client specific and not a full Hazard Analysis and Critical Control Point (HACCP) certification programme, it possessed many of the same goals and would constitute a substantial portion of a full blown program, so it was determined the HACCP framework would be used for guidance (in anticipation of an eventual completion of all HACCP Components.) The plant manager and organization were interested in achieving substantial progress toward HACCP compliance in the most efficient manner possible with the hope that the facility would ultimately achieve full certification.

The facility already possessed a manual of HACCP requirements, which the corporate headquarters had established to aid facilities throughout the country in achieving HACCP certification. However, this material was purely technical and was categorized into six different elements: Premises, Transportation and Storage, Equipment, Personnel, Sanitation and Pest Control, and Recall Procedures. The sheer volume of the three hundred page manual, and the absence of recommendations regarding implementation, made adoption of HACCP like standards overwhelming for the Calgary pie facility, particularly since it did not require full HACCP certification to attain the immediate contract. As a result, the task was to translate the existing information on HACCP requirements into a more manageable form for the local facility 
- prioritizing modules based on greatest functional benefit to the facility. Since the pie facility had no experience implementing a "formalized" food safety program, they borrowed the HACCP manual from a sister company that had implemented HACCP. While the complexity of this legacy document is questionable, it was not in the mandate of this project to remove modules, only to design a framework to make implementation more manageable.

Since the organization owned a number of food manufacturing facilities across Canada, the authors were challenged to create a flexible implementation framework and documentation process that could be used to rollout food safety procedures in other facilities across the nation as the need arose.

\section{The Hazard Analysis Critical Control Point (HACCP)}

Prioritizing safety has become critical aspect of the food industry. Over the years there have many global food safety failure incidents where contaminated food has reached the consumer. The 2007 melamine tainted pet food problem in North America (Food and Drug Administration, 2007) and 2008 melamine tainted milk products scandal in China, which resulted in many countries banning the import of milk related products from China (United Press International, 2008), are among the most recent. Confronted with issues such as Bovine Spongiform Encephalopathy (BSE), Staphylococcus Aureus and E.coli poisoning, the sector has become more conscious of the health and safety aspect of foods reaching the external end-consumer. As a result, standards such as HACCP are becoming more common throughout the industry. 
The notion of food safety is not new. The Codex Alimentarius Commission was created in 1963 by the Food and Agricultural Organization (FAO) and the World Health Organization (WHO), both organs of the United Nations (UN) to "develop food standards, guidelines and related texts such as codes of practice under the Joint FAO/WHO Food Standards Programme. The main purposes of this Programme are protecting health of the consumers and ensuring fair trade practices in the food trade, and promoting coordination of all food standards work undertaken by international governmental and non-governmental organizations" (Codex Alimentarius Commission, 2009).

The HACCP approach is a scientific system for food safety assurance (Nguyen et al., 2004). The origins of HACCP date back to the 1960s when it was developed through the combined efforts of the Pillsbury Company and the National Aeronautics and Space Administration (NASA) to prevent food safety incidents on manned space flights (Surak, 2007). Since that time, the use of HACCP has spread to the commercial food processing industry where it is now used as a tool to aid food businesses operate in a safe manner. Today, many food related businesses around the world are taking a HACCP approach to food safety and control.

In 1993 (revised in 1997) the Codex Alimentarius Commission published the first international HACCP standard. HACCP's main purpose is to provide a system whereby food businesses can control quality and safety throughout the entire food operation. In order to achieve standardization, many government agencies - including those in Europe, Canada, and the United States - require that a HACCP based food safety program follow seven guiding principles (Stringer, 1994). These seven HACCP principles of Hazard Analysis, Identification of Critical 
Points, Establishing Critical Limits, Monitoring, Correction, Verification, and Documentation (Surak, 2007) allow processors to identify hazards and then institute input controls throughout the production cycle in order to quickly react to prevent food safety problems. Thus, HACCP focuses on in-process control rather than post-process inspection (Bennet and Steed, 1999).

With requirements for companies to be formally certified in HACCP, different national auditing systems arose. In an effort to standardize food safety management globally, in 2005 the International Standards Organization (ISO) developed its ISO 22000 standard which incorporates principles of HACCP.

In order to implement a HACCP system, an establishment must meet all current program requirements and must include the implementation of prerequisite programs including facilities, transportation and storage, equipment maintenance and calibration, sanitation and pest control, personnel, and recall procedures. All segments of the food industry can use the HACCP method, which can be tailored to any process line or any type of product.

As exports becoming more prevalent in the food sector, food safety will continue to be a growing concern. Recent trends have shown that programs such as HACCP are increasingly becoming a necessity, rather than an option (Nguyen et al.). Large food retailers have set the bar for suppliers to become HACCP certified, or to develop a HACCP-like environment in order to win retail contracts. Many food manufacturing facilities have begun to review their health and safety procedures and are moving towards HACCP certification (Dulen, 1999). Governmental 
legislation will include HACCP requirements in some countries and regions. In the UK as in all EU countries, Regulation 852/2004 requires application of a system based on HACCP principles to all food business operations, with certain specific exceptions (European Commission, 2004).

Implementing HACCP like programs in the Calgary facility will help ensure its future sustainability and profitability. As the key element of the HACCP approach is its preventative nature, implementing HACCP like programs will significantly reduce the risk of any biological, physical or chemical hazards that could reach the end consumer. Further benefits of implementing the HACCP like program include increased confidence of food safety within the facility, reduced waste, and more efficient use of manpower. Legal protection and positive organizational development to cope with the demands of change represent further outcomes of adopting the HACCP approach (Taylor, 2002).

\section{Using Quality Function Deployment to Prioritize the Process}

In any implementation project, it is important to prioritize the activities that need to be conducted. In this project, the sixty-five policies contained in the company's existing HACCP manual were organized into related categories rather than by relative importance. As a result, the Quality Function Deployment (QFD) concept was applied. Yoji Akao developed the concept of QFD for new product development in the late 1960s (Jiang et al., 2007). QFD is a process that is used to translate the needs of the customer into realizable design specifications for a product or service. . The Toyota Motor Corporation credits the use of this technique for reducing the time and cost of designing cars (Davis et al., 2007). The QFD uses a matrix called the House of Quality (HOQ). 
The HOQ (Figure 2 is an example where the product to be designed is a refrigerator door) is traditionally used to identify customer requirements and corresponding design specifications for a specific product or service. Requirements are weighted based on their importance to the product in the central section or 'interior' of the house. Above this requirements matrix, interrelationships between customer and design requirements are commonly identified in a triangular 'roof'. For example in Figure 2, the first customer requirement 'Easy to close' is stongly related to the engineering design characteristic 'Effort required to close door'. Similarly the design characteristics 'Effort required to close door' and 'Door seal adhesiveness' are negatively correlated (the better the adhesiveness, the easier it closes). As a further example the figure also shows how the weighted importance rating of 131 for 'Door seal adhesiveness' is calculated. The right side of the house compares our offering to our competition's on the customer requirements while the bottom of the house compares our quality of design to our competitors. Thus the HOQ allows the company to identify what is required from a customer perspective in order to develop a successful product and then determine the engineering design requirements in order to make it happen. 


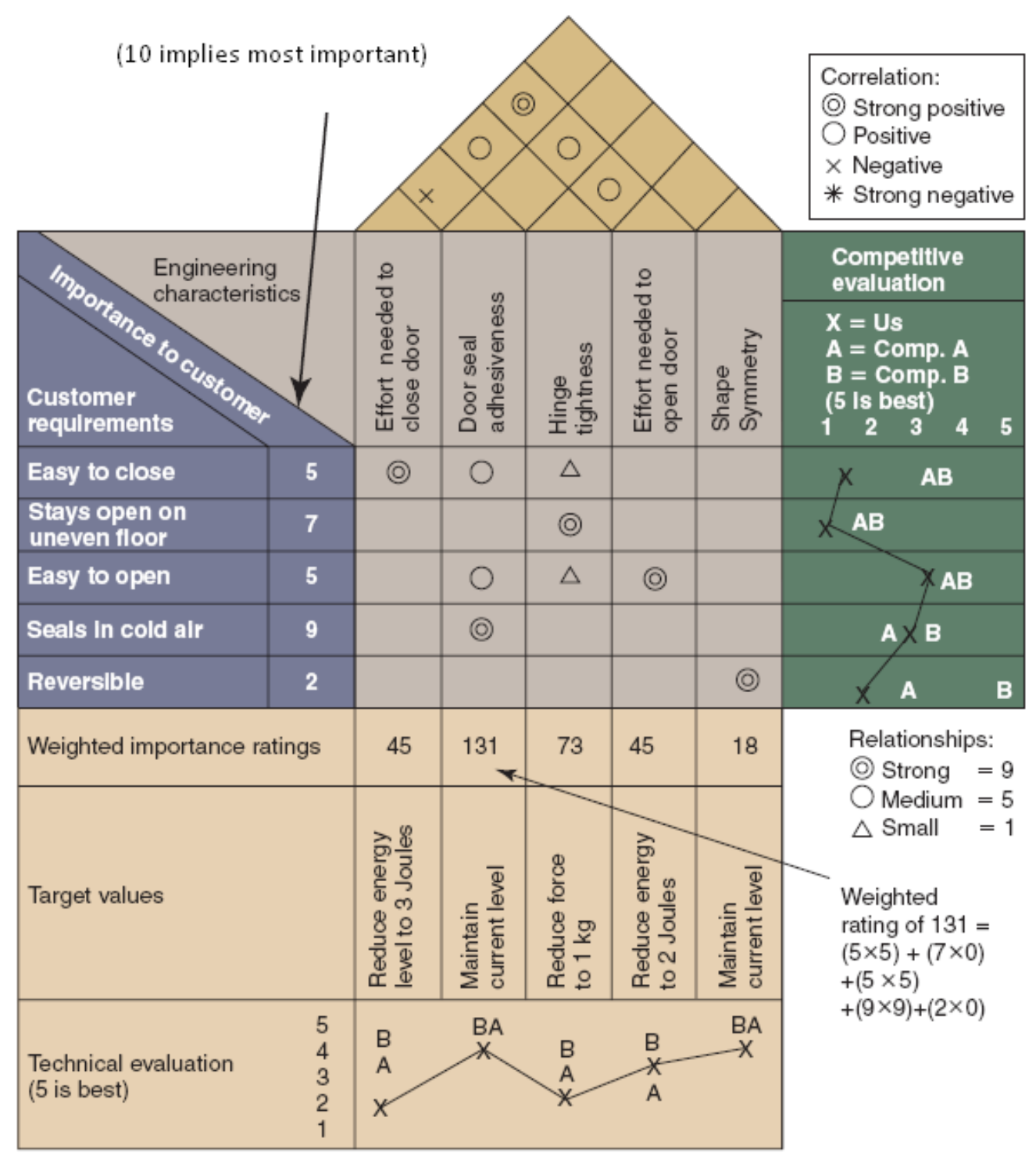

Source: M.M. Davis, J. Heineke, and J. Balakrishnan, Fundamentals of Operations Management, Toronto, Ontario: McGraw Hill Ryerson, 2nd Edition, 2007, p57.

\section{Figure 2: House of Quality diagram}

Drawing from this standard framework, a modified HOQ concept (Figure 3) was designed to prioritize the existing policies based on their correlation to the company's corporate objectives and their importance to the implementation of the required food safety practices in the most efficient manner. Similar to the original $\mathrm{HOQ}$, the interior contains the sixty-five policies as 
well as four main criteria developed to quantify the relative importance of each policy. These criteria included essential elements of the desired contract ("critical to contract" items), the assessment period for each policy as identified by HACCP, the level of documentation required, and the extent of training that would be involved. Also, as in the conventional tool, the roof of the modified HOQ identifies the interrelationships between tasks. Finally, a graph was added to the bottom of the HOQ in order to visually represent the relative importance of each policy to the implementation of HACCP-like procedures at the desired facility. Figure 3 shows only a selection of this modified House of Quality (the actual spreadsheet contains all sixty-five policies).

The left hand side of the house lists the criteria that are important to the company under the main and sub categories. Only the main categories with the associated scores are shown in Figure 3 but each had subcategories as shown in Figure 5, where part of the actual spreadsheet version of the HOQ is shown. For example the first main category consists of the sub categories that are important in helping obtain the contract from the customer. Each policy was assigned a scaled score for each of these sub categories and the main category score was based on the subcategory scores as explained later (in Figure 7). The middle of the house in Figure 3 shows a few of the sixty five policies that will be implemented as part of the food safety process. These include both HACCP prerequisite type policies (PRP) and the main HACCP type policies. In this part of the house, a scaled score is used to indicate the relevance of a policy to the criteria important to the company. These scaled scores for each policy (for example scores of 3, 0, 3, and 2.5 for policy 1.4.1.2, Building Locations and Environmental Contamination were converted into weighted scores for each main criterion (for policy 1.4.1.2 the total weighted score is 53 as a result of $8 \times 3$ 
$+0 \times 3+3 \times 3+8 \times 2.5)$, where the weights are shown at the right hand side of the house. The sixty five policies were then prioritized for implementation based on their total weights.

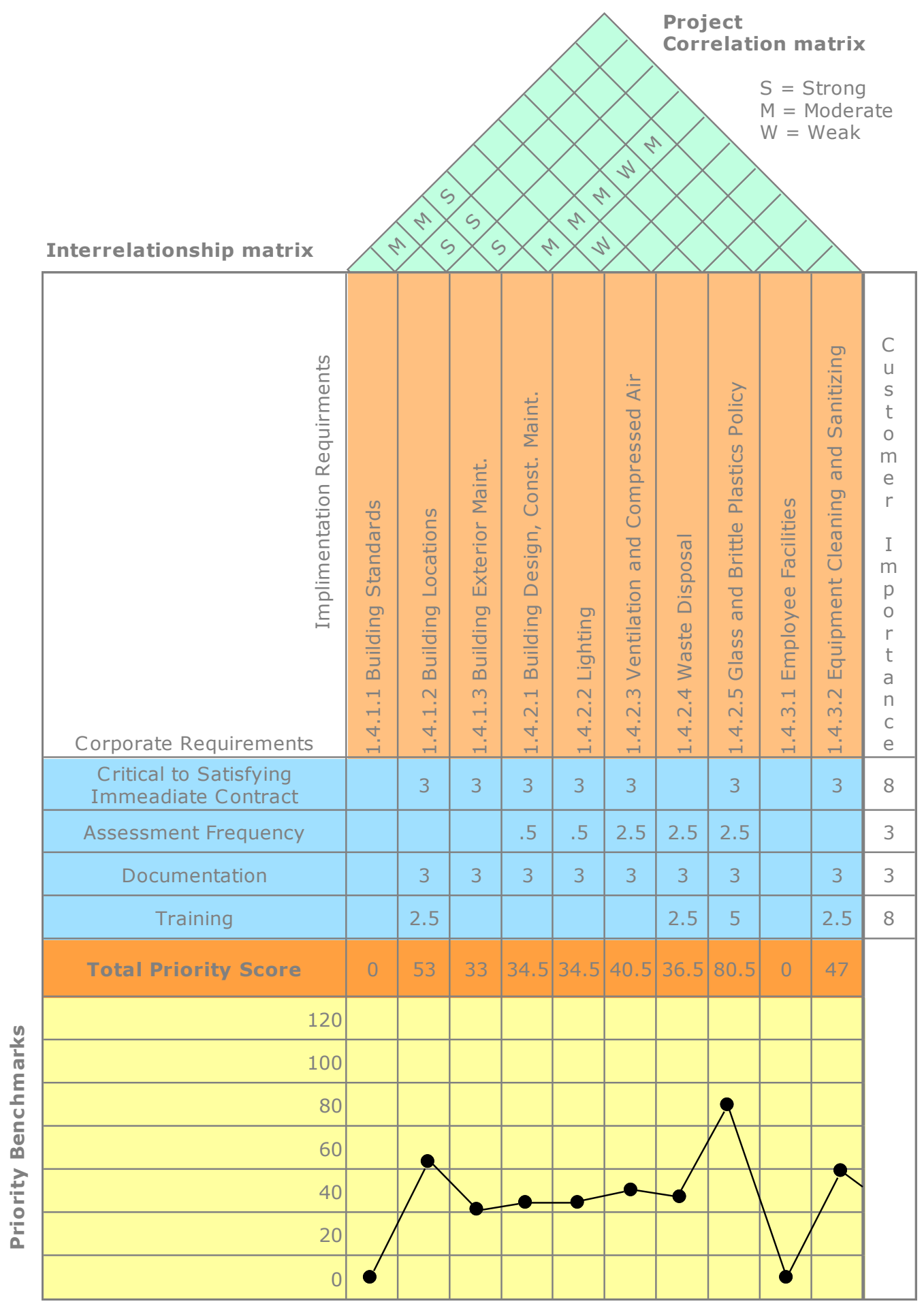

Figure 3: Simplified, "House of Quality” Demonstrating Adapted Concept 
The roof of the HOQ in Figure 3 depicts the inter-relationships between the different policies. So the roof is not related to the criteria in the left side of the tree. Consider two policies, 1.4.1.1 (Building Standards) and 1.4.2.1 (Design Construction and Maintenance). Clearly these are strongly related. Thus a ' $\mathrm{S}$ ' has been placed at the intersection of these two policies in the roof. On the other hand the relationship of 1.4.1.1. with 1.4.1.3 (Monitoring and Maintenance of Building Exterior) was considered to be moderate, ' $\mathrm{M}$ '.

When making the relationships between tasks operational to create the roof in a spreadsheet format, to keep the strength of each relationship as quantifiable as possible, a scale was developed ranging from 0 to 1 using 0.25 increments to keep the differences significant. The qualitative criteria assigned to each increment were as follows:

1.0 - Policies directly related under regular use (mentioned in other HACCP type policies)

0.75 - Policies directly related only in certain circumstances (i.e. product recalls)

0.50 - Policies indirectly related as the result of another policy

0.25 - Policies indirectly related, but no pertinent overlap between tasks

0 - No relationship between policies

So 1.0 would correspond to S, 0.75 and 0.5 to ' $\mathrm{M}$ ' and 0.25 and 0.0 to weak or ' $\mathrm{W}$ ' in Figure 3. For example, though not shown in any of the figures, the policy on Preventing Metal Contamination was given a 0.75 relationship with Consumer Complaints because not all consumer complaints are related to metal contamination (a 1-to-1 relationship); in certain 
circumstances inadequate prevention procedures can lead to customer complaints. By identifying and examining similar interrelationships, precedence between the food safety policies was established.

The best way to illustrate these tradeoffs and corresponding synergies is through exemplification of the relationship between two policies from the original HACCP manual which have a ' 1 relationship to each other. In terms of policy 6.4.1.1 Recall Procedure and 6.4.2.2, Raw Materials Tracking, the former should be implemented after the latter. If the recall capability is established prior to the tracking procedures, only those aspects of raw materials tracking that relate to product recall will be completed. This means that the facility will have to revisit the raw materials tracking policies later in the rollout process in order to complete the required nonrecall aspects of raw materials tracking. In such a case, the additional set-up and loss of synergy would represent significant inefficiency in the rollout process, whereas the early establishment of synergies would facilitate the achievement of an earlier payback. Figure 4 shows the highest ten ranked policies of the sixty five based on the weighted total scores and influences the sequence in which the tasks are done. The roof inter-relationships will also affect the sequence in which the tasks are done (this is explained later). 


\begin{tabular}{|c|} 
Policy \\
\hline \hline 1.4.5.1 Internal Plant Audit Guidelines \\
\hline \hline 6.4.1.3 Recall Capability \\
\hline \hline 6.4.1.4 Hold Policy \\
\hline \hline 6.4.2.1 Finished Product Tracking \\
\hline \hline 6.4.2.2 Raw Material Tracking \\
\hline \hline 6.4.2.3 Bulk Ingredient Tracking \\
\hline \hline 6.5.2 Crisis Management Manual \\
\hline \hline 2.4.1.2 Trailer Inspection \\
\hline \hline 2.4.2 Receiving \\
\hline
\end{tabular}

Figure 4: Prioritized list of policies

Figure 5 shows the printout of the partial spreadsheet that was used to create the HOQ shown in Figure 3. The original spreadsheet has all sixty five policies in columns. The roof is shown differently in the spreadsheet compared to Figure 3, but contains similar information. At the bottom, the overall weight of the each policy has been graphed. This gives a quick visual indication of the importance of each policy. In addition a Corporate Priorities section was added to weight the main and sub criteria (explained later).

Thus, the scoring system that was developed incorporated a combination of evaluative criteria and weightings based on critical food safety requirements, as well as the corporate priorities of the organization itself. The evaluative criteria and weightings established are shown in Figure 6. 


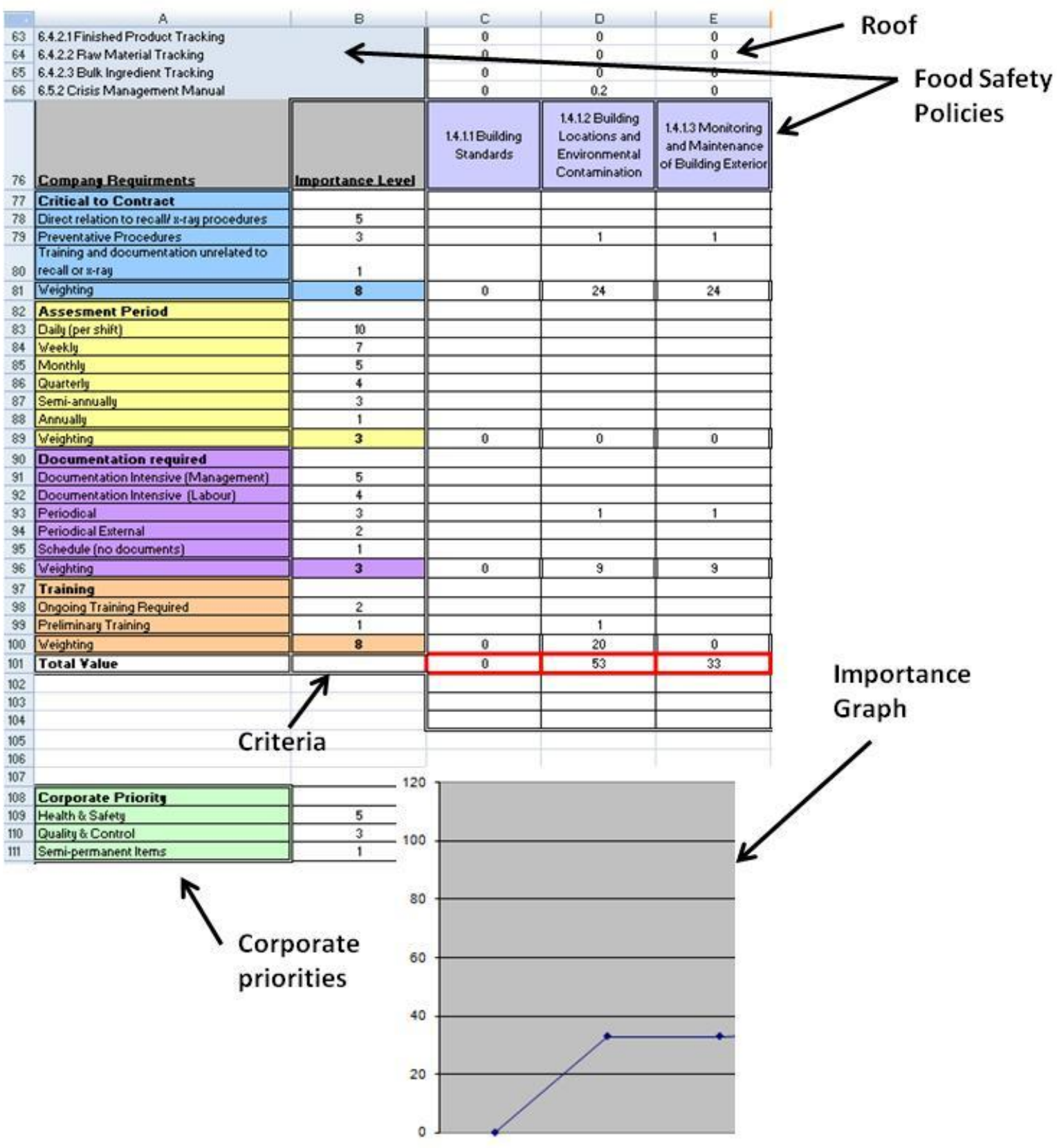

Figure 5: House of Quality for food safety programme implementation

Also under corporate priorities it is important to note that food safety is part of Quality \& Control and not part of Health \& Safety. Health \& Safety is included since this aspect is critical to the food manufacturing process and thus is relevant in our project implementation. 


\begin{tabular}{|c|c|}
\hline Company Requirments & Importance Level \\
\hline \multicolumn{2}{|l|}{ Critical to Contract } \\
\hline Direct relation to recall/ $\mathrm{x}$-ray procedures & 5 \\
\hline Preventative Procedures & 3 \\
\hline $\begin{array}{l}\text { Training and documentation unrelated to } \\
\text { recall or } x \text {-ray }\end{array}$ & 1 \\
\hline Weighting & 8 \\
\hline \multicolumn{2}{|l|}{ Assesment Period } \\
\hline Daily (per shift) & 10 \\
\hline Weekly & 7 \\
\hline Monthly & 5 \\
\hline Quarterly & 4 \\
\hline Semi-annually & 3 \\
\hline Annually & 1 \\
\hline Weighting & 3 \\
\hline \multicolumn{2}{|l|}{ Documentation required } \\
\hline Documentation Intensive (Management) & 5 \\
\hline Documentation Intensive (Labour) & 4 \\
\hline Periodical & 3 \\
\hline Periodical External & 2 \\
\hline Schedule (no documents) & 1 \\
\hline Weighting & 3 \\
\hline \multicolumn{2}{|l|}{ Training } \\
\hline Ongoing Training Required & 2 \\
\hline Preliminary Training & 1 \\
\hline Weighting & 8 \\
\hline Total Value & \\
\hline
\end{tabular}

Figure 6: Evaluative Criteria

\section{Criticality to the Desired Contract}

During the initial assessment of the production facility, management stressed that one of the main reasons for implementing a HACCP-like system of hazard and safety control was to secure contracts from a mainstream grocery-retail corporation. Using these guidelines for acquiring the contract, the authors were able to further sub-divide criteria into meaningful components and to assign weightings to each. Again, the early identification of synergies expedited goal achievement. 
Frequency of the Assessment Period Required by HACCP

In terms of ranking, the highest rank was given to those tasks required on a daily basis, whether

they require informal audits or regular procedures that must be documented (so it is like a moving picture as opposed to a snapshot, since continuous information is collected). Activities to be conducted on a weekly, monthly and semi-annual basis (more snapshots of the situation rather than a moving picture) were given lower weights respectively. The objective of giving higher priority to tasks that require more frequent assessment is to perform a preventative maintenance-like function, allowing the facility to gather accurate information over time rather than merely during the week before an audit. Immediately prior to an audit, it would be inadvisable to try to conduct an assessment of sixty-five different policies over the course of a week and expect to document each one individually. This is not only time consuming, but costly; the onerous task would encourage subversion of the system. By actively remaining current with frequent tasks, the amount of time and money saved will be substantial.

\section{Level of Documentation Required}

This next critical evaluative point may be correlated to the assessment period, but is intended to capture the quantity of documentation that must be completed during each review of a particular task. Tasks requiring larger amounts of documentation received higher ranking solely because of the amount of time that it would take to complete that task. The longer a task takes to inspect, the greater the effect it will have on a production run. 


\section{Level and Breadth of Training Required}

Although the client organization is currently training its employees, a food safety implementation requires comprehensive understanding of the training needs of the different employees. This would lead to documentation of the training that each individual should receive on each policy. It also requires an organization to build in feedback loops for retraining and provide "refresher" training courses to keep the quality of work high and maintain a focus on safety issues among factory personnel.

The policies were ranked according to four criteria (main categories) highlighted in the boxes on the left in Figure 6. Below each general criterion is a list of quantifiable attributes (sub categories) that were used to specify the degree to which each policy meets each of the criteria developed. For the Critical to Contract and Documentation Required criteria, a relative score on a scale of 1 to 5 is assigned in the column on the right. Due to the large number of sub categories required by the Assessment Period scale, a 1-10 range scale was used, while for the Training criteria, a 1-2 range scale was used.

The corporate priorities shown in the lower left part of Figure 5 were used to establish a relative weighting for each of the four criteria listed in the right hand column. Since Health and Safety was particularly important to the company, it was given a weighting of 5 . The relative importance of Quality and Control and Semi-permanent Items (movable equipment able to be relocated with the business if necessary) are likewise reflected in the weightings. 
Once these criteria weightings were established, based on corporate priorities, they were used to differentiate between the relative importance of the four established criteria. For example, the Critical to Contract scores (Figures 5 and 7) received a total weighting of 8 (in the Importance Level column) because they relate to both Health and Safety (5) and Quality and Control (3) considerations in Figure 5. Since Semi-permanent Items are not related to this specific criterion, the relative weighting of 1 was not applied to the Critical to Contract factor (if it had been added the total weighting would have increased to 9).

\begin{tabular}{|c|c|c|c|c|}
\hline Company Requirments & Importance Level & $\begin{array}{l}\text { 1.4.1.1 Building } \\
\text { Standards }\end{array}$ & $\begin{array}{l}\text { 1.4.1.2 Building } \\
\text { Locations and } \\
\text { Environmental } \\
\text { Contamination }\end{array}$ & $\begin{array}{l}\text { 1.4.1.3 Monitoring } \\
\text { and Maintenance } \\
\text { of Building } \\
\text { Exterior }\end{array}$ \\
\hline \multicolumn{5}{|l|}{ Critical to Contract } \\
\hline Direct relation to recall/ $\mathrm{x}$-ray procedures & 5 & & & \\
\hline \begin{tabular}{|l|l|} 
Preventative Procedures \\
\end{tabular} & 3 & & 1 & 1 \\
\hline $\begin{array}{l}\text { Training and documentation unrelated to } \\
\text { recall or } x \text {-ray }\end{array}$ & 1 & & & \\
\hline Weighting & 8 & 0 & 24 & 24 \\
\hline \multicolumn{5}{|l|}{ Assesment Period } \\
\hline Daily (per shift) & 10 & & & \\
\hline Weekly & 7 & & & \\
\hline Monthly & 5 & & & \\
\hline Quarterly & 4 & & & \\
\hline Semi-annually & 3 & & & \\
\hline Annually & 1 & & & \\
\hline Weighting & 3 & 0 & 0 & 0 \\
\hline \multicolumn{5}{|l|}{ Documentation required } \\
\hline Documentation Intensive (Management) & 5 & & & \\
\hline Documentation Intensive (Labour) & 4 & & & \\
\hline Periodical & 3 & & 1 & 1 \\
\hline Periodical External & 2 & & & \\
\hline Schedule (no documents) & 1 & & & \\
\hline Weighting & 3 & 0 & 9 & 9 \\
\hline \multicolumn{5}{|l|}{ Training } \\
\hline Ongoing Training Required & 2 & & & \\
\hline Preliminary Training & 1 & & 1 & \\
\hline Weighting & 8 & 0 & 20 & 0 \\
\hline Total Value & & 0 & 53 & 33 \\
\hline
\end{tabular}

Figure 7: Criteria

Each policy is scored based on the policy characteristics as listed in the Company Requirements Column in Figure 7. To score each policy, a binary code of ones and blanks are used to indicate 
the presence or absence of a relationship. Spreadsheet formulae were then used to convert these binary scores into a numerical ranking (Figure 7). For example, under Critical to Contract since Building Location (policy 1.4.1.2) is not directly related to Recall or X-Ray procedures it was given zeros (or blanks) in both corresponding rows. The ' 1 ' that appears in the second row identifies a relationship between Building Location and Preventative Procedures. This result triggers a calculation in which the score of 3 (in the Importance Level column for Preventative Procedures row) is multiplied by 8 (the number in the weighting row in the Importance Level column for Critical to Contract). As a result, a score of 24 was given to building location in the Critical to Contract characteristic. In order to convert the 1-10 and 1-2 scales to 1-5 equivalents for consistency, the total was multiplied by 0.5 and 2.5 respectively for criteria that used those scales. For example in Figure 7, the score of 20 for the Training criterion under policy 1.4.1.2 (Building Locations and Environmental Contamination) is a result of $1 \times 1 \times 8 \times 2.5$.

To derive the Total Value in the box at the bottom of the chart (Figures 5 and 7), the resulting scores (in the case of policy 1.4.1.2 the scores were 24, 9 and 20) were summed up for each characteristic (53 in the case of policy 1.4.1.2). These Total Values are graphed in the chart at the bottom or "basement" of the HOQ, resulting in a visual representation of the overall relative importance of each task, as seen in Figure 8. Recall that the numbers are then used in the prioritized rankings, an example of which was shown in Figure 4. 


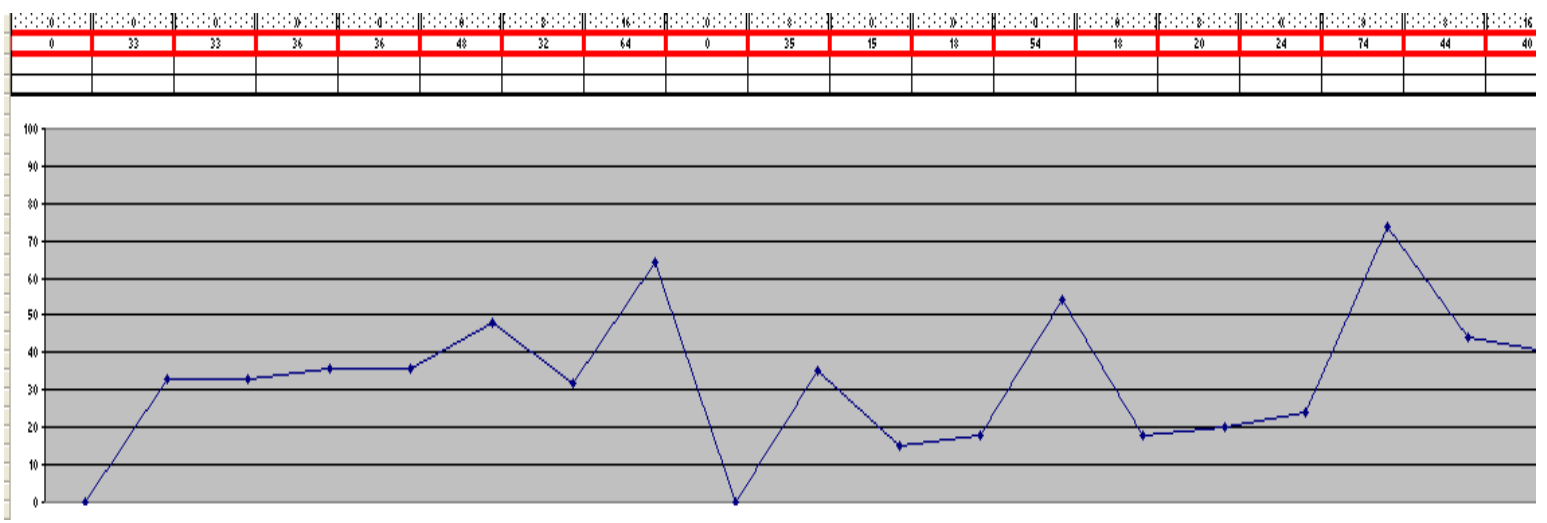

Figure 8: Importance graph

Through the prioritized ranking contained in Figure 4, the HOQ allows the facility to complete the most important tasks first in order to apply for an audit of their HACCP like procedures (for the purpose of acquiring the contract) before the full rollout is completed. As mentioned, the 'roof' of the HOQ allowed us to identify the sequence of the tasks in the implementation. While the most important tasks were given priority, we also examined the interrelationships of important tasks with other tasks. For example in Figure 4, task 1.4.5.1, Internal Plant Audit Guidelines, will have a higher priority than many other tasks and may be scheduled earlier. From the 'roof' it was also seen that this particular task had a strong relationship with 6.5.3.5, Changes in Manufacturing Site (not shown), which has a low priority. However, from an implementation effectiveness perspective, it might be better to conduct these two tasks simultaneously or one after another. This is because tasks that are interrelated may have common elements; by doing them together, the facility may avoid duplication of some of these tasks that would occur if they were done at different times in the implementation schedule. This duplication avoidance would allow for faster implementation of the required food safety procedures. 
As mentioned, in the case of the Calgary facility, the audit will not constitute an application for actual HACCP certification. Instead, the facility will be audited by their client for the successful development of a food safety system similar to HACCP in order to secure the desired contract with a retailer. Since actual HACCP implementation is not required, the prioritized task list constitutes significant efficiencies in terms of the expected duration to secure the contract.

For example, once the facility has completed the first twenty out of sixty-five tasks (31\%), they will have actually captured $50 \%$ of the total project value based on the percentage of total weighting for all tasks. Although the pie facility in Calgary intends to become fully HACCP certified in the long run, the extremely high percentage of policy rankings that are completed in the early phase of the rollout will enable the facility to secure its desired contract sooner than expected. Early results also helped to bolster management's resolve to continue with the change.

From a change management perspective, the worth of early results lies not only in cost savings, but also in more completed implementations and fewer false starts. This is quite important especially for the many small and medium size enterprise (SME) food businesses in Canada. SME's are often more strapped for cash and other resources than large organizations. Thus SME's can benefit from implementing these procedures more efficiently.

\section{Implementation}

To test assumptions, a pilot study of four rollout tasks (Trailer Inspections, Treatment of Rejected Products, Raw Materials Tracking, and Finished Products Tracking) was designed in order to introduce a representative sample of the full-scale rollout activities to organizational 
managers and facility staff. The intention was also to generate feedback regarding specific implementation challenges facing full rollout within the facility, as well as to fine-tune the rollout process to improve its chances of success in other facilities as well. This initial pilot test was also intended to provide a preliminary indication of the program's potential for success.

The tasks for the pilot study were chosen from the high priority tasks that had been ranked according to food safety requirements and organizational priorities. This was designed to comply with one of the fundamental project objectives for a prioritized schedule. The tasks selected for the pilot were further considered to be representative of the depth and involvement level of the different tasks required in the main rollout. Together, the policies corresponded to an anticipated time commitment of nine management hours and were required to be implemented within one week. As a result, the pilot study was expected to provide an accurate reflection of the average workload and intensity that would be experienced under full implementation. As the plant manager later indicated, the policies that were selected also encompassed a broad range of activities within the facility, yet were very relevant to satisfying the key concerns of the new client. The regional process improvement co-ordinator commented that the prioritization of modules served to enable "quick wins" for the pie facility, motivating them further.

It was expected that the intensive documentation required by many of the company's food safety policies would be particularly challenging for the pie facility. As a result, it was considered essential to provide the plant manager with a preliminary sense of the documentation procedures that would be required in a full-scale rollout. A pilot study was considered the best way to achieve this, since implementing a small-scale rollout within the facility would generate a realistic indication of the daily impact of the full-scale implementation requirements. In broader 
terms, the pilot was intended to acquaint the plant manager with the rollout format and would guide the facility's expectations of the full-scale rollout to come.

On completion of the selected tasks within the duration of a week, the plant was expected to provide both written and verbal feedback on their experience within eight to twelve days of the pilot start date. In addition to written feedback provided upon completion of the necessary policies, an informal discussion with the plant manager was scheduled one week after the pilot had ended. This provided an indication of the manager's overall comprehension of the rollout format and food safety requirements, the ease of use of the materials prepared, and any unanticipated problems that arose during the pilot implementation.

Subsequent to the pilot rollout, the plant manager at the Calgary facility indicated the value added by the new process. He considered the rollout format to be very helpful and thorough in assessing current operations, and challenging previous assumptions about the wisdom of sequentially arranged projects. The requested policies were implemented within the desired time frame. The manager was clearly enthusiastic about the full scale rollout and had considerable confidence that the deliverables provided would help him achieve a quicker and more comprehensive food safety implementation within the facility. The pilot study also alerted the organization to a need to provide additional resources within the facility to meet project deadlines before the full implementation got underway. Traditionally, the company would be forced to scramble to provide these resources, only aware mid project. In the words of the regional process improvement manager, "it was the very different from the 'manage by crisis' mentality which permeated the organization". 
Although the plant manager considered the rollout format to be very thorough after the pilot had been conducted, the level of assessment required initially overwhelmed him. Nevertheless, when he went through the material himself, he realized that the assessment and reassessment activities were relatively low intensity and extremely valuable to the implementation process. In his words, "it was a measure twice, cut once" approach. As a result, the pilot study demonstrated how imperative it is to provide an adequate explanation of intentions of each subtasks, so that users do not approach the material as a series of unnecessary rework and checking. .

\section{Conclusion and suggestions}

This paper focused on the application of QFD to help a company implement HACCP like food safety procedures in an efficient manner. The pilot study indicated that these suggestions were useful to the organization.

As a result of the recognized relationships and prioritized schedules made possible through the House of Quality, the suggested implementation program will enable facilities to achieve quicker and more effective progress towards establishing food safety procedures. By creating a HACCPlike environment by using this effective method, the pie facility in Calgary will benefit from greater marketability for their products much sooner than would otherwise be possible. In addition, this process increases the plant's ability to secure additional contracts with larger food retailers, since many require HACCP certification or HACCP-like procedures implemented. As a result, the company believes that these deliverables will have a significant influence on the plant's future profitability. 


\section{References}

1. Anonymous, Asian countries ban Chinese milk products, UPI.com, September 21, 2008, retrieved December 14, 2008.

2. Bennet, W.L., and Steed, L.L. (1999), “An integrated approach to food safety", Quality Progress, February, pp 37-42.

3. Codex Alimentarius Commission (2009), http://www.codexalimentarius.net/web/index_en.jsp, retrieved, February 20, 2009.

4. Davis, M.M., Heineke, J. and Balakrishnan J., (2007), Fundamentals of Operations Management, Toronto, Ontario: McGraw Hill Ryerson, 2nd Edition.

5. Dulen, J. (1999). "Food Safety Forcing Industry to Change”. Restaurants \& Institutions. 109, 19, pp 142-143.

6. European Commission (2004), http://ec.europa.eu/food/food/biosafety/hygienelegislation/guidance_doc_8522004_en.pdf, retrieved February, 10, 2009.

7. Food and Drug Administration, (2007), http://www.fda.gov/oc/opacom/hottopics/petfood.html, retrieved, February 2, 2009.

8. Jiang, J.C, Shiu, M.L., and Tu, M.H. (2007) "QFD's Evolution in Japan and the West", Quality Progress; July, pp 30-37.

9. Nguyen, T., Wilcox, A., and Aung, M. (2004) "Food safety and quality systems in Canada", International Journal of Quality and Reliability Management, 21, 6, pp 655671.

10. Stringer, M.F. (1994), "Safety and quality management through HACCP and ISO 19000”, Dairy Food and Environmental Sanitation, , 14, 8, 428-481.

11. Surak, J.G. (2007), “A Recipe for Safe Food: ISO 22000 and HACCP, Quality Progress, October, pp 21-27.

12. Taylor, E. (2002). HACCP in Small Companies: benefit or burden? Lancashire Postgraduate School of Medicine and Health, University of Central Lancashire, Preston, UK. 